\title{
MS/MS analysis of four scorpion venoms from Colombia: a descriptive approach
}

\author{
Sebastian Estrada-Gómez ${ }^{1,2 *}$ (1), Leidy Johana Vargas-Muñoz ${ }^{3}$ (D), Monica Maria Saldarriaga-Córdoba ${ }^{4}$, \\ Arie van der Meijden ${ }^{5}$ (1) \\ ${ }^{1}$ Toxinology Research Group - Serpentarium, University of Antioquia (UdeA), Medellín, Antioquia, Colombia. \\ ${ }^{2}$ School of Pharmaceutical and Food Sciences, University of Antioquia (UdeA), Medellín, Antioquia, Colombia. \\ ${ }^{3}$ School of Medicine, Cooperative University of Colombia, Medellín, Antioquia, Colombia. \\ ${ }^{4}$ Center for Research in Natural Resources and Sustainability, Bernardo O'Higgins University, Santiago, Chile. \\ ${ }^{5}$ Research Center in Biodiversity and Genetic Resources (CIBIO), University of Porto, Vila do Conde, Portugal.
}

\section{Keywords:}

Scorpion

Venom

Colombia

MS analysis

Toxins

Sodium channels
* Correspondence: sebastian.estrada@udea.edu.co https://doi.org/10.1590/1678-9199-JVATITD-2020-0173 Received: 25 November 2020; Accepted: 01 March 2021; Published online: 09 July 2021.

\begin{abstract}
Background: Scorpions are widely known for the neurotoxic effects of their venoms, which contain peptides affecting ionic channels. Although Colombia is recognized for its scorpion diversity, only a few studies are available describing the venom content.

Methods: In this descriptive study, we analyzed the MS/MS sequence, electrophoretic and chromatographic profile linked to a bioinformatics analysis of the scorpions Chactas reticulatus (Chactidae), Opisthacanthus elatus (Hormuridae), Centruroides edwardsii (Buthidae) and Tityus asthenes (Buthidae) from Colombia.

Results: Each scorpion showed a specific electrophoretic and chromatographic profile. The electrophoretic profiles indicate the presence of high molecular mass compounds in all venoms, with a predominance of low molecular mass compounds in the Buthidae species. Chromatographic profiles showed a similar pattern as the electrophoretic profiles. From the MS/MS analysis of the chromatographic collected fractions, we obtained internal peptide sequences corresponding to proteins reported in scorpions from the respective family of the analyzed samples. Some of these proteins correspond to neurotoxins affecting ionic channels, antimicrobial peptides and metalloproteinaselike fragments. In the venom of Tityus asthenes, the $\mathrm{MS}^{\mathrm{n}}$ analysis allowed the detection of two toxins affecting sodium channels covering $50 \%$ and $84 \%$ of the sequence respectively, showing $100 \%$ sequence similarity. Two sequences from Tityus asthenes showed sequence similarity with a phospholipase from Opisthacanthus cayaporum indicating the presence of this type of toxin in this species for the first time. One sequence matching a hypothetical secreted protein from Hottentotta judaicus was found in three of the studied venoms. We found that this protein is common in the Buthidae family whereas it has been reported in other families - such as Scorpionidae - and may be part of the evolutionary puzzle of venoms in these arachnids.

Conclusion: Buthidae venoms from Colombia can be considered an important source of peptides similar to toxins affecting ionic channels. An interesting predicted antimicrobial peptide was detected in three of the analyzed venoms.
\end{abstract}




\section{Background}

Scorpion venoms have evolved over 400 million years into a complex, but well elaborated library of toxins that can differ dramatically in its effects among species [1]. The diversity of protein compounds (peptides, proteins and enzymes) and nonprotein compounds (salts, neurotransmitters, etc.) make these venoms a promising source of molecules with antibacterial, antifungal, antiviral, antimalarial and anticancer activities [2-5], and a potential source for the design of new drugs $[6,7]$. The most active molecules displaying such activities are peptides that can be split into non-disulfide bridge (NDBP) and disulfide bridge (DBP) peptides, showing alpha helical linear motifs or inhibitory cysteine knots respectively. The NDBP compounds were reported recently and the main characteristic of these molecules is the lack of disulfide bridges, the cationic net charge, the sequence diversity, the hemolytic and antibacterial activity, and the relatively low molecular mass (1-4 kDa) [8]. Most of these peptides possess an amphipathic alpha-helical structure like those reported for different cationic antimicrobial molecules [3,8-15]. DBP are the major molecules described in these venoms and are characterized by containing around 30 to 70 amino acids residues and three or four disulfide bridges [3,8-15]. The major targets of these toxins are ionic channels like sodium (Nav), potassium (Kv), chlorine (Clv) or calcium (Cav) channels in the nervous system, blocking or gating the channel mechanism and thereby exhibiting a neurotoxic activity.

Despite the diversity of scorpions in Colombia, only a few studies are available describing the venom content [16-19]. No studies have been found describing the venom content of Chactas reticulatus, Opisthacanthus elatus, Centruroides edwardsii or Tityus asthenes. The only available studies report the phospholipase $A_{2}$ content and activity in the venom of $O$. elatus, and the intraspecific biochemical differences detected in the venom of C. edwardsii from two regions in Colombia [16,17]. The genus Tityus is probably one of the must studied scorpions in South America, but from Colombia the only available studies of this genus are the proteomic analysis of Tityus pachyurus reporting specific toxins affecting $\mathrm{Na}^{+}$and $\mathrm{K}^{+}$channels $[18,20]$, and the peptide content description of Tityus macrochirus [19]. There is no study available on T. asthenes. Venom from $C h$. reticulatus is still completely unexplored and the venom of this species had hitherto not been described or analyzed.

Here we report the first partial amino acid sequences including the post-translational modifications (PTM) of the venom from Ch. reticulatus, O. elatus, C. edwardsii and T. asthenes, with the respective electrophoretic and chromatographic profile with analysis of their predicted antimicrobial activity and the report of different partial toxins that may affect ionic channels.

\section{Methods}

\section{Species selection}

Scorpions with epidemiologic and clinical importance in Antioquia (North-west Colombian Andean region) according to Otero et al. [21-23] Chactas reticulatus, Opisthacanthus elatus, Centruroides edwardsii and Tityus asthenes (with no or scarce previous reports), were selected for this research and kept in captivity in the serpentarium of the University of Antioquia, Medellin (COLBIOFAR-149) with water ad libitum and fed with insects (Periplaneta americana and Tenebrio molitor). One specimen of Chactas reticulatus was sourced from the municipality of El Retiro (El Salado sector) at 2100 meters above sea level (m.a.s.l), while seven specimens of Opisthacanthus elatus born in captivity from an individual from the municipality of Remedios - Antioquia were used. Four specimens of Centruroides edwardsii were from two localities in the municipality of Amaga and Medellín at 1250 m.a.s.l. and 1450 m.a.s.l. respectively. Furthermore, six specimens of Tityus asthenes originating from the municipality of Carepa (Urban area) at 26 m.a.s.l. were used.

\section{Venom extraction}

Venom extraction was carried out using electro-stimulation. Metal electrodes, wetted with a saline solution, were carefully positioned on the metasoma and a block signal with an amplitude of $18 \mathrm{~V}$ at $40-60 \mathrm{~Hz}$ was applied twice with an interval of $5 \mathrm{sec}$ using a custom-made electro-stimulator (model 01). Collected venom was transferred to dry low-protein binding vials, freeze-dried and stored at $-20^{\circ} \mathrm{C}$ until use. These procedures were in accordance with the ethical principles in animal research adopted by the World Health Organization for the characterization of venoms. After each extraction, all animals were kept alive in captivity.

\section{Electrophoretic profiles}

All electrophoretic profiles of crude venoms were analyzed using $12 \%$ sodium dodecyl sulfate polyacrylamide gels (SDS-PAGE) according to Laemmli [24], and stained with Coomassie blue $\mathrm{R}-250$. Molecular weights were estimated using standard low range markers standards (Bio-Rad). Venoms were loaded at a concentration of $1.5 \mathrm{mg} / \mathrm{ml}$ and a final volume of $20 \mu \mathrm{L}$. Venom concentrations were assessed following the Biuret method using Bio-Rad Protein Assay reagent and bovine serum albumin (BSA) as standard [25-27]. A 3D scatterplot representation with the number of compounds detected in each venom based in their absence-presence in every species was performed using the software SIGMAPLOT v. 14 (Systat Software, San Jose, CA). To do so, compounds detected in each venom were grouped in four different ranges: $14 \mathrm{kDa}$ to $31 \mathrm{kDa}, 31 \mathrm{kDa}$ to $45 \mathrm{KDa}, 45$ $\mathrm{kDa}$ to $97.4 \mathrm{kDa}$, and above $97.4 \mathrm{KDa}$, and plotted. Additionally, venoms showing potentially toxins affecting ion channels in the MS/MS analysis were run on 10\% TRIS-TRICINE gels, and stained with Coomassie blue R-250. Molecular weights were estimated using standard broad range standards (Bio-Rad). Quantification of volumes and calculation of molecular weights were performed using the software GelAnalyzer 19.1, available at: http://www.gelanalyzer.com/ [28]. Molecular weights were calculated using the known values of the standard broad rank markers (Bio-Rad): $200 \mathrm{kDa}, 116 \mathrm{kDa}, 97 \mathrm{kDa}, 66 \mathrm{kDa}, 45 \mathrm{kDa}$, $31 \mathrm{kDa}, 21 \mathrm{kDa}, 14 \mathrm{kDa}, 6 \mathrm{kDa}$. To estimate the molecular 
weight, we used a simple exponential fit approximation and according to the $\mathrm{Rf}$ (retention factor, measured as the band distance migrated/gel length) of each analyzed band.

\section{Chromatographic profile}

We followed the methodology proposed by Fernandez et al. [29] and adapted by Estrada et al. [16,17] for arachnid venoms separation. One milligram of whole venom was dissolved in $200 \mu \mathrm{L}$ of solution A ( $0.1 \%$ trifluoroacetic acid - TFA, in water) and centrifuged at $3500 \mathrm{~g}$. The supernatant was then applied to a reverse-phase RESTEK C18 column $(250 \times 4.6 \mathrm{~mm})$, and separated on a Shimadzu Prominence HPLC. Proteins were eluted by a gradient towards solution $\mathrm{B}(0.1 \%$ TFA in acetonitrile - ACN 99\%) as follows: $5 \%$ B for $5 \mathrm{~min}, 5-15 \%$ B over $10 \mathrm{~min}$, $15-45 \%$ B over $60 \mathrm{~min}$, and $45-70 \%$ B over $12 \mathrm{~min}$ at a flow rate of $1.0 \mathrm{ml} / \mathrm{min}$. The chromatographic run was monitored at $215 \mathrm{~nm}$ and fractions were collected, freeze-dried and stored at $-20^{\circ} \mathrm{C}$ until used.

\section{Peptide mass determination by high-resolution LC- MS}

For Ch. reticulatus, C. edwardsii and T. asthenes we selected the peaks with the best intensity and resolution from the RP-HPLC chromatograms. For O. elatus, we collected the major peak of the phospholipase region according to Estrada et al. [17], looking for a deeper characterization of this region. We wanted to see if this region exclusively contained phospholipase proteins or if there were more components co-eluting in the region. Selected dried fractions were digested and submitted to the MS/MS equipment as explained below.

\section{Sample digestion}

Sequence grade Lys-C/Trypsin (Promega) was used to enzymatically digest the venom samples. The samples were reduced and alkylated. All digestions were carried out in the Barocycler NEP2320 (PBI) at $50^{\circ} \mathrm{C}$ under $20 \mathrm{kpsi}$ for 2 hours. Digested samples were cleaned over C18 spin columns (Nest Group) and dried. Resulting pellets were re-suspended in $97 \%$ purified $\mathrm{H}_{2} \mathrm{O} / 3 \% \mathrm{ACN} / 0.1 \%$ formic acid (FA). A volume of $5 \mu \mathrm{L}$ was used for nano LC-MS/MS analysis.

\section{LC-MS/MS}

Fractions were run on a nano Eksigent 425 HPLC system coupled to the Triple TOF 5600 plus (Sciex, Framingham, MA). The method used for analysis was 120 minutes at $300 \mathrm{~nL} /$ minute over the cHiPLC nanoflex system. The trap column was a Nano cHiPLC $200 \mu \mathrm{m} \times 0.5 \mathrm{~mm}$ ChromXP C18-CL $3 \mu \mathrm{m}$ x $120 \AA$ followed by the analytical column, the Nano cHiPLC $75 \mu \mathrm{m} \mathrm{x}$ $15 \mathrm{~cm}$ ChromXP C18-CL $5 \mu \mathrm{m} \times 120 \AA$ A. The sample was injected into the Triple TOF 5600 and through the Nanospray III source equipped with an emission tip (New Objective, Woburn, MA, USA). Peptides from the digestion were eluted from the columns using a mobile phase A of purified $\mathrm{H}_{2} \mathrm{O} / 0.1 \%$ formic acid (FA) and a mobile phase B of ACN/0.1\% FA. With a flow rate of 0.3 $\mu \mathrm{L} / \mathrm{min}$, the method started at $95 \% \mathrm{~A}$ for 1 minute followed by a gradient of $5 \%$ B to $35 \%$ B in 90 minutes and from $35 \%$ B to $80 \%$ B in 2 minutes. Eighty percent of B was held for 5 minutes before being brought to $5 \% \mathrm{~B}$ and held for 20 minutes. PTM are reported for each containing peptide.

\section{Data analysis}

The data acquisition was performed monitoring 50 precursor ions at $250 \mathrm{~ms} / \mathrm{scan}$. Mascot Daemon v.2.4.0 (Matrix Science) was used for similarities searches against the different databases downloaded from the UniProt and NCBI websites. Data analysis was run in the Bindley Bioscience Center at Purdue University. Multiple sequence alignment was completed using the Clustal Omega software (http://www.ebi.ac.uk/Tools/msa/clustalo/) of $\mathrm{MS} / \mathrm{MS}$ sequences from each venom with the respective similar peptide/protein.

\section{Bioinformatics analysis}

The search for similar peptides/proteins matching KISSV[X] NKDKI peptide was performed in Protein Information Resource (PIR) databases [30,31]. Specifically peptide matching using Apache Lucene-based search engine [32], using as query sequence the peptide without specifying the residue in the bracket $[\mathrm{X}]$, and each of the following residues A,I,V,S and $\mathrm{N}$ according to MS/MS analysis. The search was performed in the databases UniProtKB/Swiss-Prot with isoforms.

\section{Evaluation of the physicochemical properties}

The corresponding physicochemical properties of identified peptides following an in silico analysis, resulting in metrics for peptide length (residues), molecular weight, total hydrophobic ratio, net charge at physiological $\mathrm{pH}$, and the Boman Index, were determined using the Antimicrobial Peptide Database Calculator and Predictor (APD3 http://aps.unmc.edu/AP/) [33].

\section{Results}

\section{Electrophoretic and chromatographic profiles}

The venom from each species showed a specific electrophoretic profile, and some differences were detected among the species (Figure 1A). Visibly, differences are specially observed in the high molecular mass compound (HMMC) region above $31 \mathrm{kDa}$ (where HMMC like metalloproteinases are commonly found), with some compounds migrating close to $14 \mathrm{kDa}$ and $21 \mathrm{kDa}$ (where HMMC like phospholipases are commonly found) (Figure 1A). Venoms from C. edwardsii and T. asthenes (Buthidae) showed a very similar profile with the majority of compounds distributed above $31 \mathrm{kDa}$ and with few compounds around $14 \mathrm{kDa}$ (according to Figure 1B). The non-buthidae venoms from O. elatus, Ch. reticulatus shows electrophoretic profiles with visible differences; most compounds are distributed among $97 \mathrm{kDa}$ and $45 \mathrm{kDa}$ 
(see Figure 1B). A specific difference was observed below $31 \mathrm{kDa}$ in the O. elatus venom, were at least 3 compounds were detected migrating close to $14 \mathrm{kDa}$ (see Figure 1B).

As observed in the electrophoretic pattern, the chromatographic profile showed clear differences between venoms from each species (Figure 2). In all cases, we obtained complex chromatograms with good resolution and well defined peaks. As seen in the electrophoretic profile, venoms from C. edwardsii and T. asthenes (Buthidae) showed a similar profile within this sub-group, while the Ch. reticulatus venom showed a specific profile, displaying differences between families. Compounds from Buthidae venoms elute below $38 \%$ of $\mathrm{ACN}$, while the non-Buthidae compounds elutes up to $50 \%$ of ACN or $60 \%$ of ACN for O. elatus and Ch. reticulatus respectively. In all cases, we selected well defined peaks for the MS/MS analysis (arrows in Figure 2).

\section{MS/MS analysis}

From all selected peaks, we obtained internal peptide sequences, matching different proteins from Buthidae scorpions. Only in the venoms from C. edwardsii and T. asthenes we found internal

A

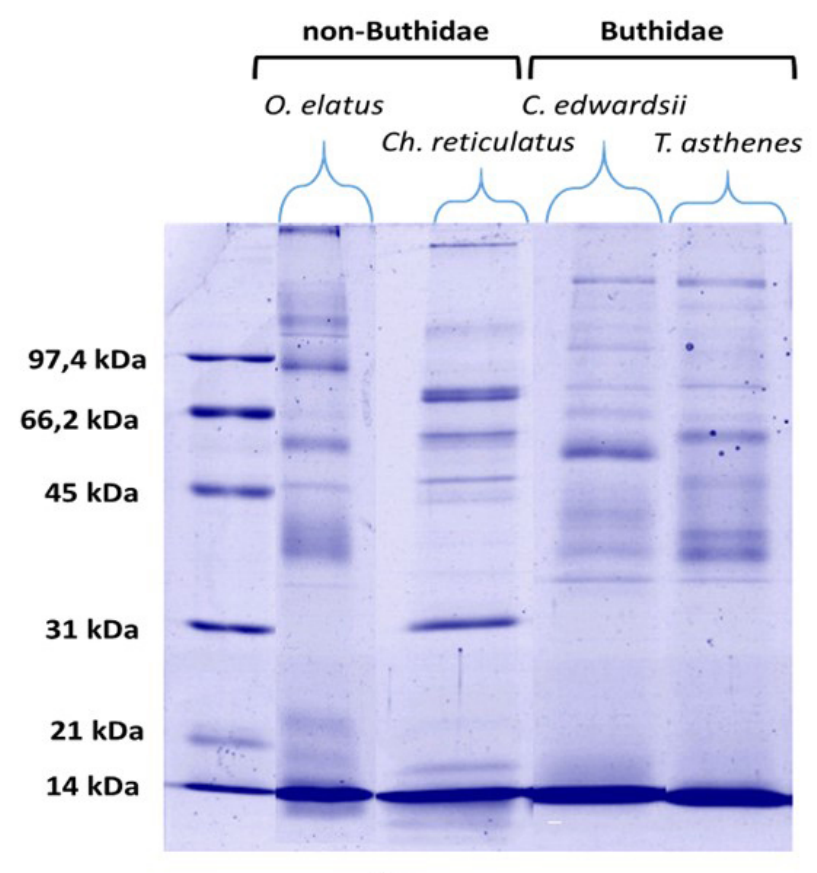

B

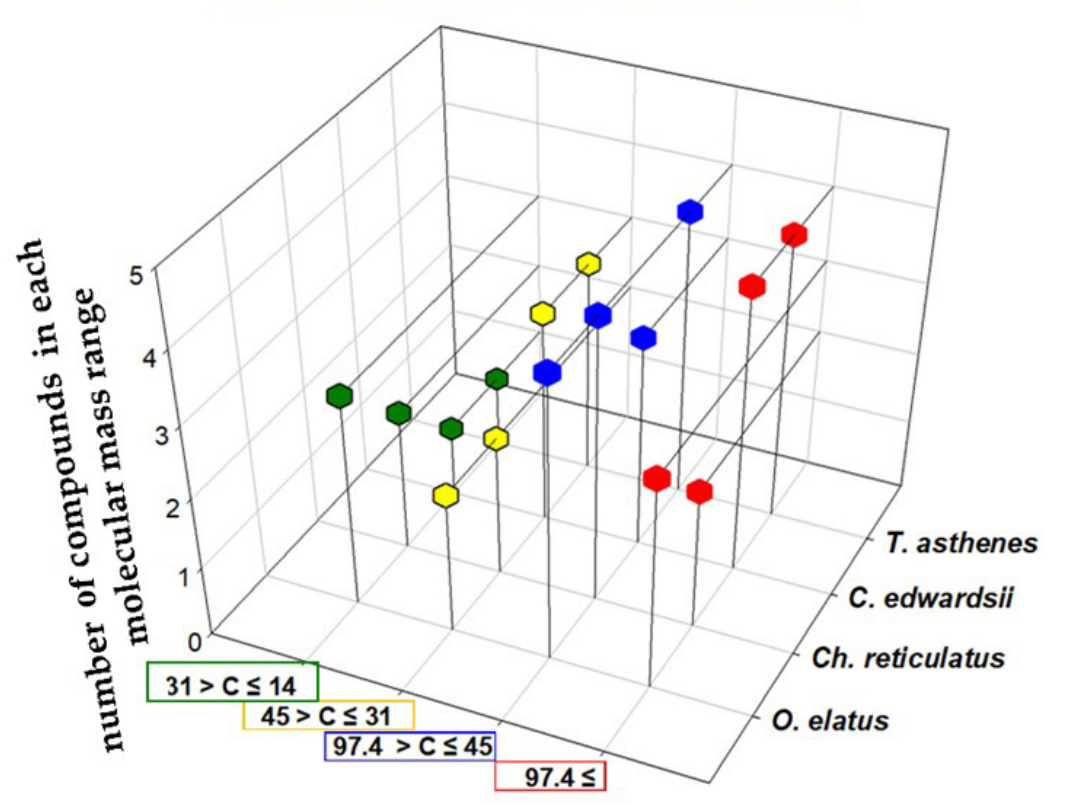

Figure 1. (A) Crude venom SDS-PAGE profile in a 12\% gel under reducing conditions of Opisthacanthus elatus, Chactas reticulatus, Centruroides edwardsii and Tityus asthenes. (B) 3D scatterplot of the number of compounds found in each molecular mass range of every species. Both figures show visible differences among species in relation to electrophoretic pattern and number of compounds, with the $T$. asthenes and $C$. edwardsii profiles being more similar. Green dots indicate compounds with a molecular range between $14 \mathrm{kDa}$ and $31 \mathrm{kDa}$. Yellow dots indicate compounds with a molecular range between $31 \mathrm{kDa}$ and $45 \mathrm{kDa}$. Blue dots indicate compounds with a molecular range between $45 \mathrm{kDa}$ and $97.4 \mathrm{kDa}$. Red dots indicate compounds with a molecular range of $97.4 \mathrm{kDa}$ or above. Letter C: compound. 

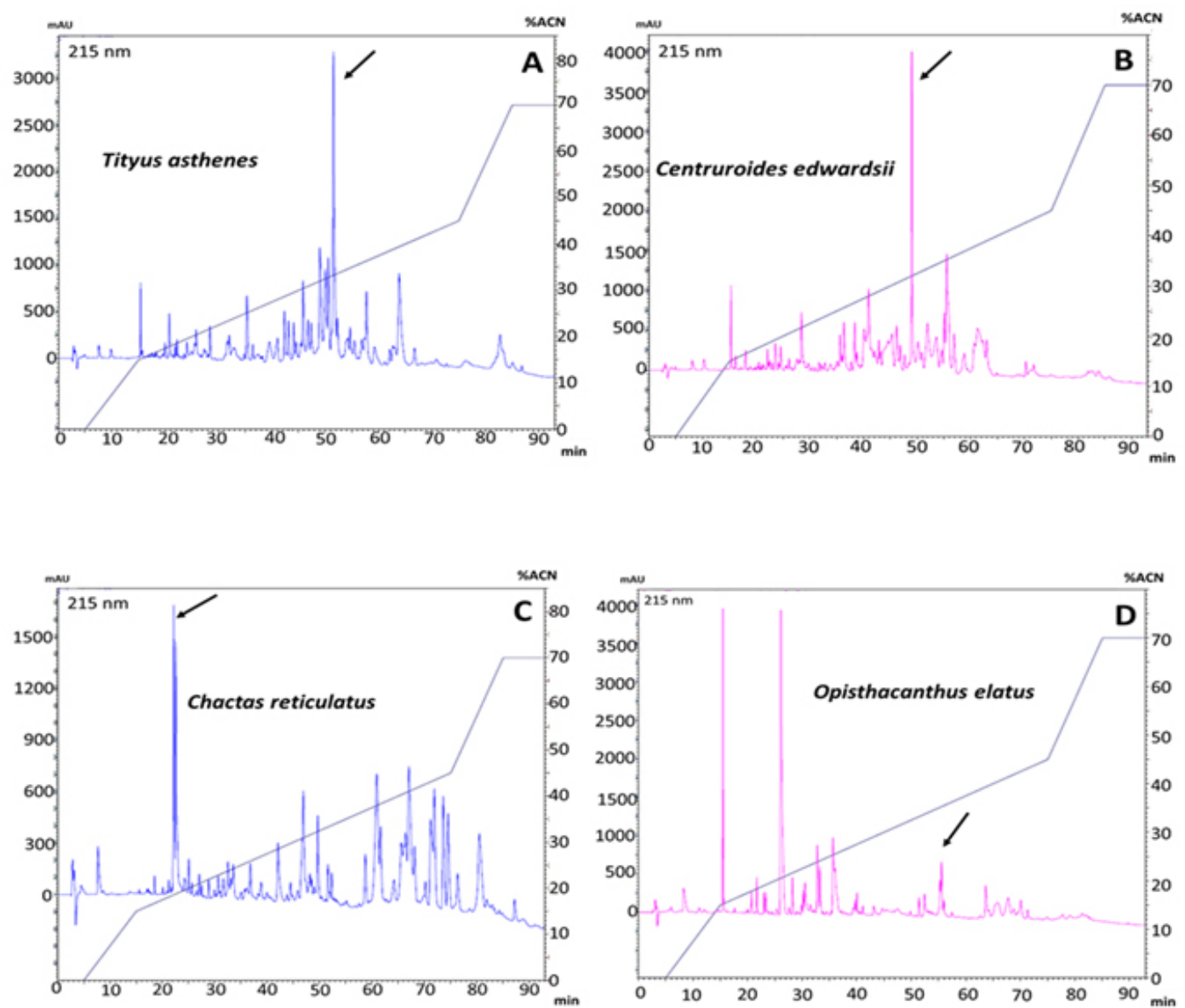

Figure 2. Venom chromatographic profile. RP-HPLC chromatographic profiles of the crude venom of all scorpions using a C18 column (250 mm-4.6 mm): (A) T. asthenes, (B) C. edwardsii, (C) Ch. reticulatus and (D) O. elatus. Elution gradient used: $0-70 \%$ of acetonitrile ( $99 \%$ ACN in TFA $0.1 \%)$. The run was monitored at $215 \mathrm{~nm}$. Arrows indicate fraction subjected to MS/MS analysis.

peptides matching neurotoxins affecting ion channels. A TRISTRICINE gel corroborate the presence of compounds with an estimated molecular masses similar to these neurotoxins (around to $6.5 \mathrm{kDa}$ ) in both venoms (see Figure 3).

The MS/MS analysis of all scorpion venoms showed toxins similar to neurotoxins affecting potassium or sodium channels, beta-neurotoxin, antimicrobial peptides and metalloproteinaselike or phospholipase-like fragments (Figure 4).

In $C h$. reticulatus venom we found only one sequence that matched a hypothetical secreted protein from Hottentotta judaicus (Table 1). From the venom of O. elatus, we detected different sequences matching antimicrobial peptides, scorpinelike peptides and opistoporin, additional to the previous reported sequence matching a phospholipase $\mathrm{A}_{2}$ from $O$. cayaporum (also found here) (Table 1). These compounds were all previously reported in the venom of O. cayaporum. Of the six fragments detected in C. edwardsii, three sequences showed similarity with three different peptides affecting ion channels. One fragment matched a potassium channel toxin alpha-KTx 2.2 from Centruroides margaritatus and other with a potassium channel toxin alpha-KTx 2.1 from Centruroides noxius (Table 1). Other sequences showed similarity with peptides from Hottentotta judaicus and Mesobuthus gibbosus. Venom from T. asthenes showed more than 26 hits with different proteins and peptides and the main matched organism of T. asthenes sequences belongs to a species from the same genus, Tityus discrepans (Table 1). As observed in the electrophoresis, with compounds in the range of 14-31 kDa and 31-45 kDa, some fragments from T. asthenes matched metalloproteinases (venom metalloprotease-1) and phospholipases from other Buthidae (Mesobuthus eupeus) and Hormuridae (Opisthacanthus cayaporum) scorpions.

The MS analysis of $T$. asthenes allowed the detection of sequences covering above $50 \%$ of two toxins affecting sodium channels. Six fragments matched one toxin affecting sodium channels $\left(\mathrm{Na}_{\mathrm{v}}\right)$ from Centruroides noxius (Toxin Cn11), covering $84 \%$ of this toxin (Figure $5 \mathrm{~A}$ ). Additionally, two more fragments, with a similarity of $100 \%$, covered $50 \%$ of the toxin Ts1 from $T$. serrulatus (Buthidae), a proven voltage-gated sodium channel (Nav) gating-modifier (see Figure 5B).

\section{Bioinformatics analysis}

In all venoms, except $O$. elatus, we found a sequence fragmentKISSV[IN]NKDKI - with residue number six varying between $\mathrm{I}$ (isoleucine) or $\mathrm{N}$ (asparagine), depending on the species. 


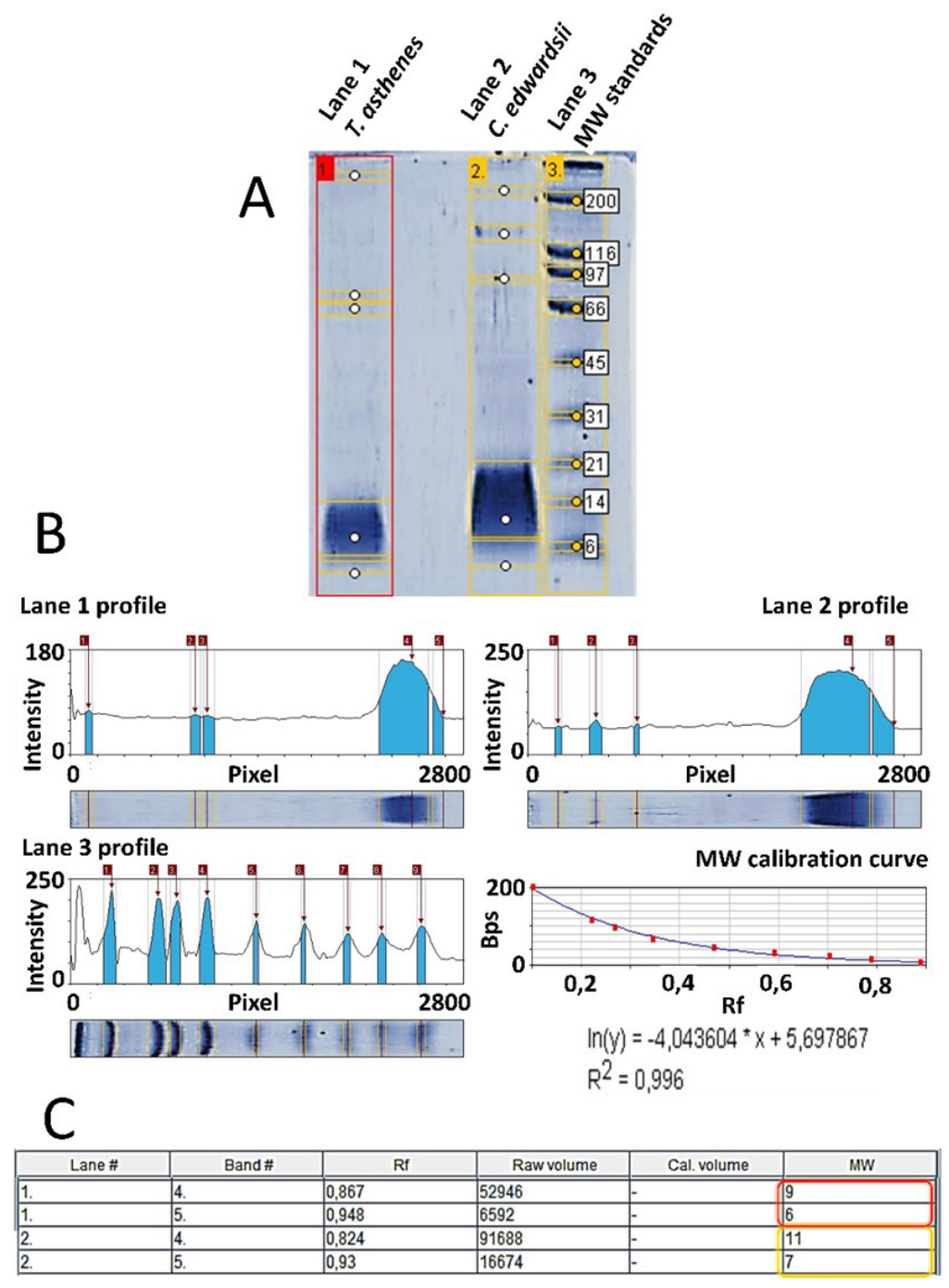

Figure 3. (A) TRIS-TRICINE electrophoresis analysis of T. asthenes (lane \#1) and C. edwardsii (lane \#2) venoms. (B) Intensity profile of each detected lane and bands in the TRIS-TRICINE electrophoresis gel. The bottom of each image shows the respective electrophoretic run. The intensity of each band is reported in arbitrary units. (C) Estimated molecular weights of bands detected below $6.5 \mathrm{kDa}$, red box for lane \#1 (T. asthenes) and yellow box for lane \#2 (C. edwardsii). Molecular weight estimation according the MW calibration curve analyzed with a simple exponential fit approximation with a $\mathrm{R}^{2}$ of 0.99 . Rf: retention factor, $\mathrm{MW}$ : estimated molecular weight.

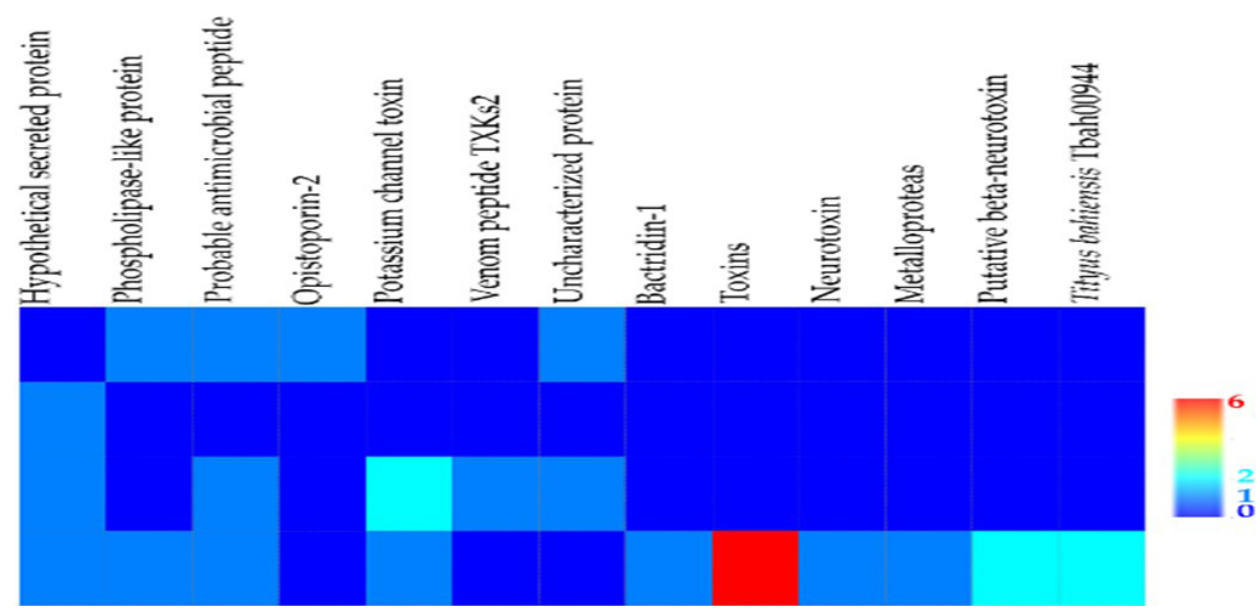

Figure 4. Matrix plot performed with presence/absence data of matched peptide family with MS/MS peptide sequence found in Chactas reticulatus, Opisthacanthus elatus, Centruroides edwardsii and Tityus asthenes venoms. 


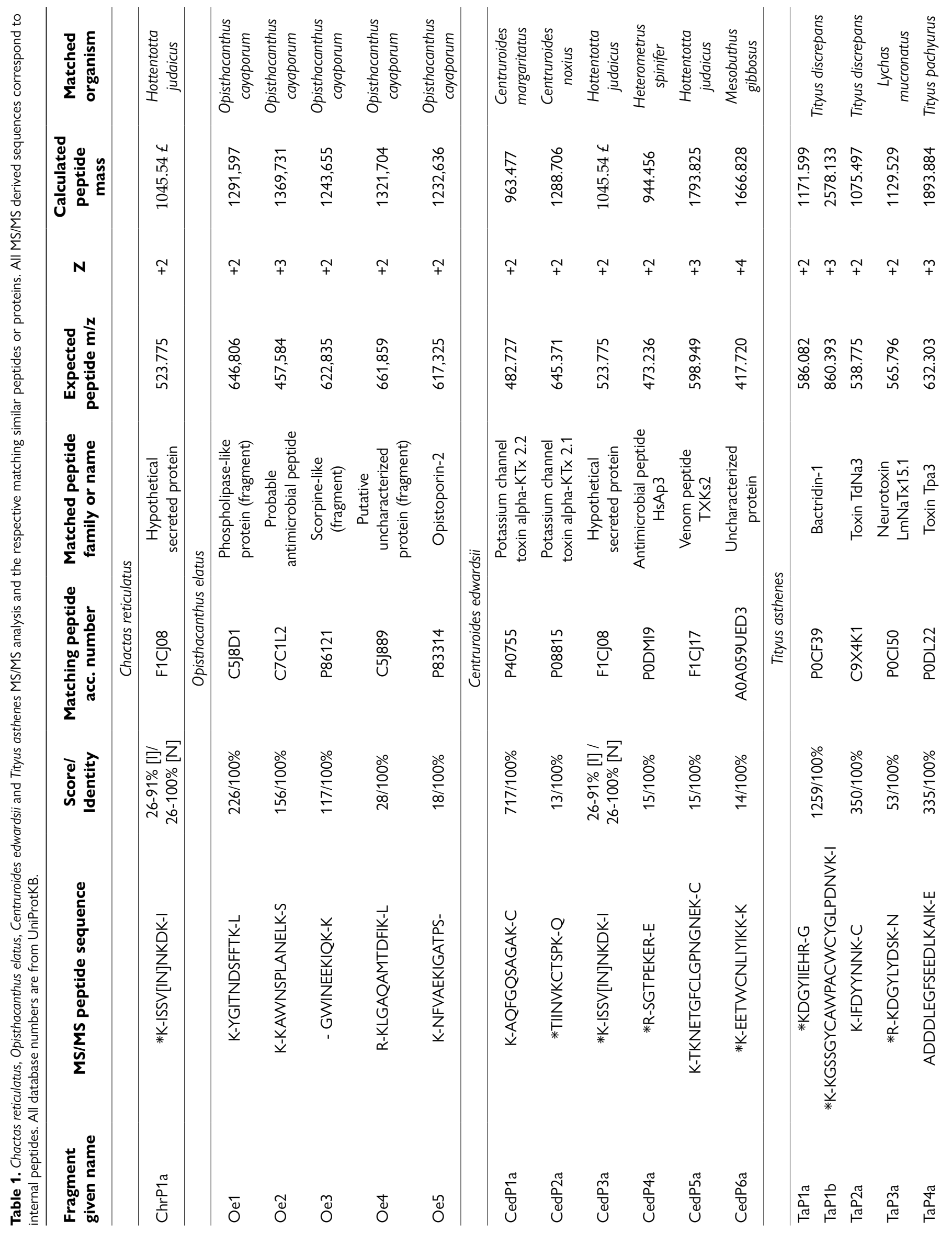




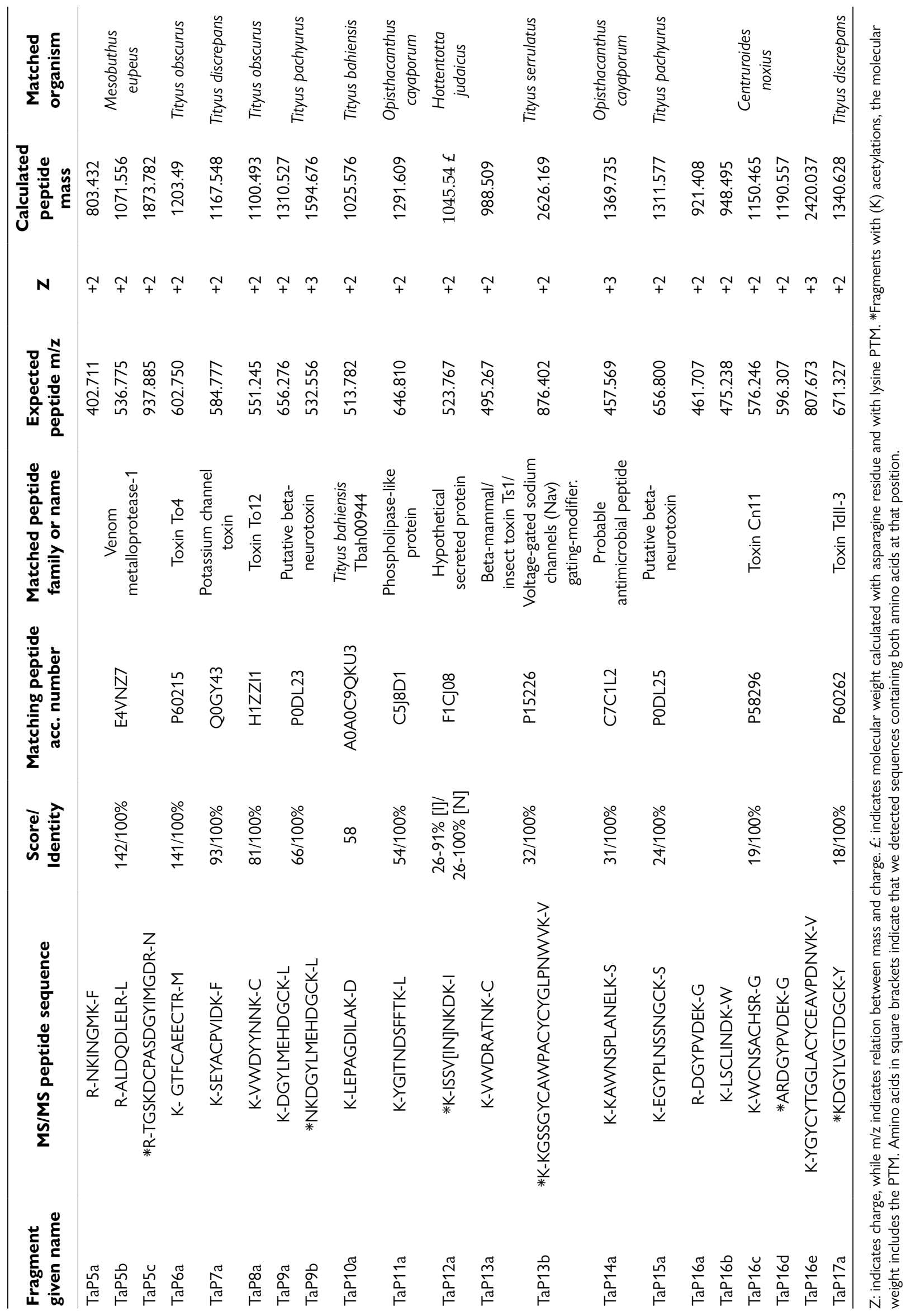


A

TaP16e

TaP16c

TaP16b

TaP16a

TaP16d

sp $|\mathrm{P} 58296|$

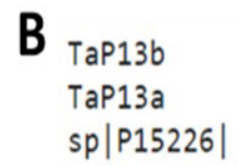

KYGYCYTGGLACYCEAVPDNVKV--.-- -

KWCNSACHSRG-

KLSCLINDKW --

-RDGYPVDEKG -

ARDGYPVDEKG

ARDGYPVDEKGCKLSCLINDKWCNSACHSRGGKYGYCYTGGLACYCEAVPDNVKVWTYETNTC

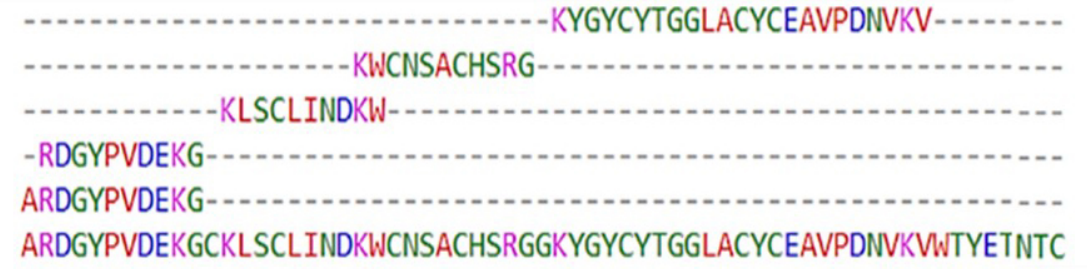

23

11

10

10

11

63

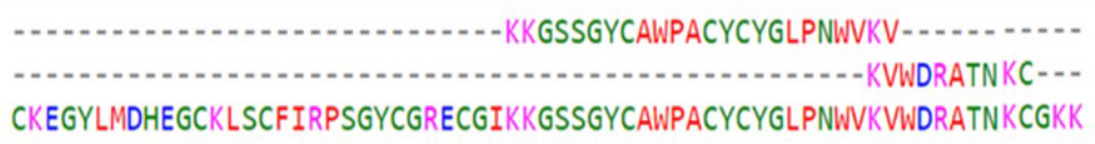

24

10

65

Figure 5. (A) Pairwise alignment of fragments TaP16a, TaP16b, TaP16c, TaP16d, TaP16e, from T. asthenes, matching peptide Cn11 (sp|P58296|) from Centruroides noxius, sodium channels blocker (Nav). (B) Pair-wise alignment of fragments TaP13a and TaP13b from T. asthenes, matching mature peptide beta-mammal/insect toxin Ts1 a voltage-gated sodium channels (Nav) gating-modifier.

The search for similar sequences that included the fragment, without specifying the residue in position number six [X], did match with a sequence of Hottentotta judaicus with accession number F1CJ08. When the search was performed with the residue "A", it matched with seven sequences, five of Androctonus bicolor (A0A0K0LCB5, A0A0K0LCC6, A0A0K0LCC9, A0A0K0LCD6 and A0A0K0LCD7), one of Odontobuthus doriae (A0A0U3YCW0), and one of Mesobuthus eupeus (E4VP36). Finally, with one of the residues "IVSN", it matched with a previously reported fragments in the venoms of Androctonus amoreuxi, Pandinus imperator, Tityus fuhrmanni and Grosphus grandidieri [34]. Figure 6 shows the families and species where the fragment has been reported before.

\section{Evaluation of the physicochemical properties}

Predicted physicochemical properties of - KISSV[AIVSN] NKDKI - based in the amino acid content and the net charge of this peptide, indicates that the fragment may be part of an antimicrobial protein (Table 2). Despite all possible amino acids sequences detected in the KISSV[X]NKDKI peptide, all conformations show a net predicted charge of $2+$ and a similar hydrophobic residue percentage. Only peptides with residues KISSV[AIV]NKDKI are predicted to form an alpha helix showing a higher hydrophobic residue percentage. According to our MS/MS results, only KISSV[X]NKDKI with the Isoleucine (I) amino acid residue in the sequences from Chactas reticulatus, Centruroides edwardsii and Tityus asthenes may enhance antimicrobial activity in these venoms.

\section{Discussion}

Peptides are the dominant components of scorpion venoms and the primary source of their pharmacological diversity, becoming a natural source of bioactive compounds [6,36]. For this reason, scorpions are the focus of different studies attempting to describe the peptide content of their venoms in recent years.
Although most scorpion venom electrophoresis are carried out using TRIS-TRICINE gels to visualize low molecular mass compounds, using SDS-PAGE gels allowed us to see the rich content of HMMC in each species.

Buthidae venoms from Colombia are rich in peptides affecting ionic channels and peptides with antimicrobial activity [34]. Although Tityus and Centruroides are widely distributed and studied in Colombia, most of the studies are focused on epidemiological aspects. Only four studies are available analyzing the composition of the venom of these two epidemiologically relevant scorpion genera; two characterizing the venom from T. pachyurus, one characterizing the peptide content of Tityus macrochirus, and one reporting an intraspecific difference in the biochemical and biological activity of C. edwardsii venom from two populations in different regions in Colombia [16]. In the former, the authors described the presence of a potent potassiumchannel blocker and putative sodium scorpion channel toxins (NaScTxs) in the Tityus genus [18,20]. The present work indicates that T. asthenes and C. edwardsii seems to be an important source of toxins affecting ionic channels. Matched toxins from T. asthenes and C. edwardsii correspond to neurotoxins reported in other Buthidae scorpions like Tityus discrepans, Tityus pachyurus, Tityus obscurus, Centruroides margaritatus or Centruroides noxius, from Colombia, México, Venezuela or Brazil [18,37]. In $T$. asthenes we detected 16 different fragments from this venom (TaP2a, TaP3a, TaP6a, TaP7a, TaP8a, TaP9a, TaP9b, TaP13a, TaP13b, TaP15a, TaP16a, TaP16b, TaP16c, TaP16d, TaP16e, TaP17a), matching nine different toxins affecting sodium channels and one affecting potassium channels [37-39]. All these toxins, reported in other scorpions, can inhibit sodium currents, inhibit the inactivation of the activated channels, affect sodium channel activation by shifting the voltage of activation toward more negative potentials, or block the voltage-gated potassium channels. Some of these toxins were described in other Tityus species from different countries. Fragments TaP16a, TaP16b, TaP16c, TaP16d, TaP16e, matching $84 \%$ of the Cn11 amino 

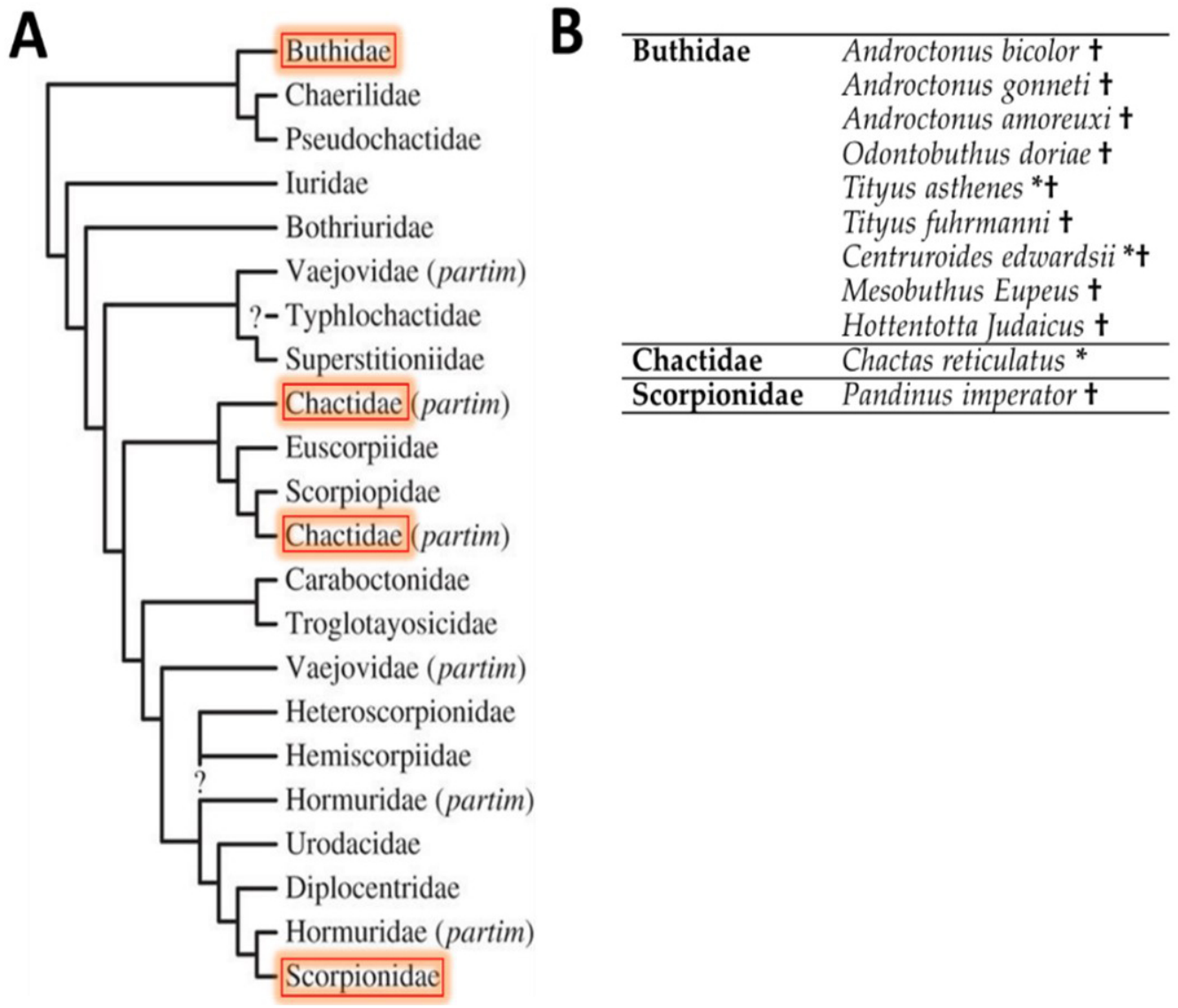

Figure 6. (A) Families and (B) species where the fragment KISSV[AIVSN]NKDKI had been reported. *Species published in this study; + : match with query peptide. Distribution of scorpion families according to Sharma et al. [35]. Figure adapted from Sharma et al. [35].

Table 2. Physicochemical properties of the KISSV[AIVSN]NKDKI peptide calculated in APD3 (Antimicrobial Peptide Calculator and Predictor).

\begin{tabular}{|c|c|c|c|c|c|}
\hline \multirow{2}{*}{ Physicochemical properties } & \multicolumn{5}{|c|}{ MS/MS peptide sequence } \\
\hline & $\mathbf{A} * *$ & $\mid * *$ & $\mathbf{V} * *$ & S* & $\mathbf{N} *$ \\
\hline Length (residues) & 11 & 11 & 11 & 11 & 11 \\
\hline Molecular weight (MW) & 1.202 .406 & 1.244 .487 & 1230.46 & 1.218 .405 & 1.218 .405 \\
\hline Net charge at physiological PH (7.4) & 2 & 2 & 2 & 2 & 2 \\
\hline Hydrophobic residues (\%) & 36 & 36 & 36 & 27 & 27 \\
\hline Borman Index (kcal/mol) & 2.1 & 1.81 & 1.89 & 2.57 & 2.57 \\
\hline Similar Peptide /\% & AP01814/45.45 & AP02863/ 42.85 & AP02863/ 41.66 & & \\
\hline
\end{tabular}

*According to APD3 prediction, this peptide cannot form an alpha helix that is long enough to be an AP. **Predicted short alpha-helical cationic antimicrobial peptide.

acid sequence from C. noxius (Buthidae) and fragments TaP13a and TaP13b covering $50 \%$ of the toxin Ts1 from T. serrulatus (Buthidae) with a similarity of $100 \%$ in both cases, indicating the presence of sodium channel blockers in this venom. In the venom of $C$. edwardsii, two more fragments (CedPla and CedP2a) were detected, matching peptides affecting potassium channels, and were described as potent inhibitors of voltagegated potassium channels $[40,41]$. Although there is no previous report of the peptide or protein content of these two Buthidae scorpions from Colombia (T. asthenes and C. edwardsii), venom characterization of other Buthidae indicates that neurotoxins are the major content of these venoms, just as seen in our results [42-44]. We found four more fragments (TaP1a, TaP1b, TaP14a and CedP4a) from T. asthenes and C. edwardsii that are similar to antimicrobial peptides (AMP), active against Gram-negative and Gram-positive bacteria and fungi [13]. Many AMP have been described before in scorpion venoms $[3,45]$, but this is the first report of the presence of these bio-active compounds in scorpion venoms from Colombia. Venom content from O. elatus seems to be very similar to that reported in O. cayaporum from Brazil [46]. All five fragments matched toxins reported in $O$. cayaporum, including a phospholipase-like protein and a probable 
antimicrobial peptide [46]. The O. elatus phospholipase region analyzed seems to be not exclusive for the elution of this proteins but also antimicrobial peptides. We expected to find many more sequences in major fraction in the Ch. reticulatus venom (as observed in the T. asthenes venom), the lack of recovered peptide families may be due to their absence, or due to there being very few Chactas sequences in the reference database.

SDS-PAGE and TRIS-TRICINE electrophoresis together with the MS/MS analysis allowed the detection of different HMMC and low molecular mass compounds (LMMC) in both Tityus and Centruroides venoms matching molecular weighs similar to neurotoxins, phospholipases or metalloproteinases. In Colombia, this HMMC had only been described in the venom from the scorpion Opisthacanthus elatus and the spider Pamphobeteus verdolaga [17,47], but never in Buthidae scorpions. HMMC are quite commonly distributed proteins in arachnids. Their main biological activities include housekeeping functions or enzymatic activities, like phospholipases or hyaluronidase [48-52]. Despite the clinical importance of these proteins, they are among the less studied venom components. These HMMC had been previously reported in the venoms from T. bahiensis, where the $32.69 \%$ of its venom content correspond to metalloproteinases [42].

In all cases, further proteomic studies are necessary to complete the MS/MS analysis of these important sources of bioactive compounds.

In three of the four venoms analyzed by mass spectrometry, we detected a common fragment with a variant in the $6^{\text {th }}$ amino acid residue where a Isolecucine (I) can be replaced by an Asparagine (N) (K-ISSV[IN]NKDK-I) with a PTM with (K) acetylations. This fragment matches a hypothetical secreted protein from Hottentotta judaicus with unknown biological activity. We previously detected the same fragment in the venoms from Pandinus imperator, Grosphus grandidieri, Tityus fuhrmanii and Androctonus amoreuxi with an additional variant in the $6^{\text {th }}$ amino acid residue where the amino acids mentioned above can be replaced by Alanine (A), Valine (V) or cysteine (C) [34]. Is very important to consider that according to prediction results, only KISSV[X]NKDKI with the Isoleucine (I) amino acid residue in their sequences from Chactas reticulatus, Centruroides edwardsii and Tityus asthenes may enhance an antimicrobial activity in these venoms.

Currently, 20 scorpion families are recognized [35,53], and only 45 species have a transcriptomic analysis available, including Buthidae (with 22 species) and non-buthidae families (with 23 species). Considering that the Buthidae family has the highest number of species with a transcriptome available, proteins similar with our peptide (KISSV[IN]NKDKI) have mainly been described in the family Buthidae, with some reports in the Chactidae and Scorpionidae families. The presence of this protein mainly in the Buthidae family may suggests a recruitment of this peptide before Buthidae split from non-buthid species, as suggested by He et al. [54] for Chaerilus tricostatus and Chaerilus tryznaithe (Chaerilidae). Their evolutionary analysis showed that the NaTx, $\beta$-KTx, and bpp-like toxin types were recruited into the venom before the lineage split between Buthidae and non-
Buthidae families. Similarly, Ma et al. [55] studied the evolution of the scorpion venom by comparative transcriptome analysis of venom glands and phylogenetic analysis of shared types of venom peptides and proteins between buthids and euscorpiids. This analysis revealed that at least five of the seven common types of venom peptides and proteins were likely recruited into the scorpion venom proteome before the lineage split between Buthidae and Euscorpiidae (i.e. basal in extant scorpions) with their corresponding genes undergoing individual or multiple gene duplication events.

\section{Conclusion}

The analyzed Buthidae venoms from Colombia may be considered a rich source of peptides similar to toxins affecting ionic channels. The Opisthacanthus elatus phospholipase region is composed not only of phospholipases but also of peptides with compounds similar to antimicrobial peptides. An interesting predicted antimicrobial peptide was detected in three of the analyzed venoms. When compared with the literature, this peptide is present in other scorpion families indicating a probable ancient peptide. The search for similar proteins that match with query peptides suggest that multiple types of venom peptides, including antimicrobial peptides, could have been recruited into the venom proteome during, before or at the basal split in the phylogeny of extant scorpions. In all cases, further proteomic studies are necessary to complete the MS/MS analysis of these important sources of bioactive compounds.

\section{Acknowledgments}

Authors are grateful to Jorge Asprilla and Janet García from the Serpentario, Universidad de Antioquia (UdeA). Specials thanks are also due to Jesus David Bedoya Medina for the support.

\section{Availability of data and materials}

All data generated or analyzed during this study are included.

\section{Funding}

This research is funded by the Universidad de Antioquia (UdeA) through the Young Researcher Program and Project CIQF-284 financed by the Programa de Gestión Tecnologica, Vicerectoría de Extensión - UdeA, and Comité para el Desarrollo de la Investigación CONADI, Universidad Cooperativa de Colombia. AvdM is supported by a grant of Fundação para a Ciência e Tecnologia (FCT, Portugal) under the Programa Operacional Potencial Humano - Quadro de Referência Estratégico Nacional funds from the European Social Fund and Portuguese Ministério da Educação e Ciência (SFRH/BPD/101057/2014). AvdM is also funded by FEDER funds through the Operational Program for Competitiveness Factors - COMPETE and by National Funds through FCT - Foundation for Science and Technology under the project FCT-PTDC/BIA-EVF/2687/2012 and FCOMP-010124-FEDER-028340. 


\section{Competing interests}

The authors declare that they have no competing interests.

\section{Authors' contributions}

All authors contributed with the manuscript preparation, experiments and data analysis. All authors read and approved the final manuscript.

\section{Ethics approval}

The present study was approved by the Comite de Ética para Experimentación en Animales de la Universidad de Antioquia (CEEA, University of Antioquia - Resolución Rectoral 18084), minute no. 123-2019.

\section{Consent for publication}

Not applicable.

\section{References}

1. van der Meijden A, Koch B, van der Valk T, Vargas-Muñoz LJ, Estrada-Gómez S. Target-Specificity in Scorpions; Comparing Lethality of Scorpion Venoms across Arthropods and Vertebrates. Toxins (Basel). 2017 Oct 4;9(10):312.

2. Ortiz E, Gurrola GB, Schwartz EF, Possani LD. Scorpion venom components as potential candidates for drug development. Toxicon. 2015 Jan;93:125-35.

3. Vargas LJ, Estrada-Gomez S. Purification and Characterization of Venom Components as Source for Antibiotics. Mini-Rev Org Chem. 2014 May;11(1):15-27.

4. Vargas Munoz LJ, Estrada-Gomez S, Escobar J. Snake and scorpion toxins venoms, a natural source of molecules with antimicrobial activity. CURARE. 2015;2.

5. Almaaytah A, Tarazi S, Mhaidat N, Al-Balas Q, Mukattash TL. Mauriporin, a Novel Cationic a-Helical Peptide with Selective Cytotoxic Activity Against Prostate Cancer Cell Lines from the Venom of the Scorpion Androctonus mauritanicus. Int J Pept Res Ther. 2013 May 21;19:281-93.

6. Estrada G, Villegas E, Corzo G. Spider venoms: a rich source of acylpolyamines and peptides as new leads for CNS drugs. Nat Prod Rep. 2007 Feb;24(1):145-61.

7. Rash LD, Hodgson WC. Pharmacology and biochemistry of spider venoms. Toxicon. 2002 Mar;40(3):225-54.

8. Cao LY, Dai C, Li ZJ, Fan Z, Song Y, Wu YL, et al. Antibacterial Activity and Mechanism of a Scorpion Venom Peptide Derivative in vitro and in vivo. Plos One. 2012;7(7):e40135.

9. Cao LY, Li ZJ, Zhang RH, Wu YL, Li WX, Cao ZJ. StCT2, a new antibacterial peptide characterized from the venom of the scorpion Scorpiops tibetanus. Peptides. 2012 Aug;36(2):213-20.

10. Cociancich S, Goyffon M, Bontems F, Bulet P, Bouet F, Menez A, et al. Purification and characterization of a scorpion defensin, a $4 \mathrm{kDa}$ antibacterial peptide presenting structural similarities with insect defensins and scorpion toxins. Biochem Biophys Res Commun. 1993 Jul 15;194(1):17-22.

11. Corzo G, Escoubas P, Villegas E, Barnham KJ, He WL, Norton RS, et al. Characterization of unique amphipathic antimicrobial peptides from venom of the scorpion Pandinus imperator. Biochem J. 2001 Oct 1;359(Pt 1):35-45.

12. Corzo G, Villegas E, Gomez-Lagunas F, Possani LD, Belokoneva OS, Nakajima T. Oxyopinins, large amphipathic peptides isolated from the venom of the wolf spider Oxyopes kitabensis with cytolytic properties and positive insecticidal cooperativity with spider neurotoxins. J Biol Chem. 2002 Jun 28;277(26):23627-37.
13. Diaz P, D'Suze G, Salazar V, Sevcik C, Shannon JD, Sherman NE, et al. Antibacterial activity of six novel peptides from Tityus discrepans scorpion venom. A fluorescent probe study of microbial membrane $\mathrm{Na}+$ permeability changes. Toxicon. 2009 Nov;54(6):802-17.

14. Miyashita M, Sakai A, Matsushita N, Hanai Y, Nakagawa Y, Miyagawa HA. Novel Amphipathic Linear Peptide with Both Insect Toxicity and Antimicrobial Activity from the Venom of the Scorpion Isometrus maculatus. Biosci Biotechnol Biochem. 2010;74(2):364-9.

15. Ramirez-Carreto S, Quintero-Hernandez V, Jimenez-Vargas JM, Corzo G, Possani LD, Becerril B, et al. Gene cloning and functional characterization of four novel antimicrobial-like peptides from scorpions of the family Vaejovidae. Peptides. 2012 Apr;34(2):290-5.

16. Estrada-Gomez S, Cupitra NI, Arango WM, Munoz LJ. Intraspecific variation of centruroides edwardsii venom from two regions of Colombia. Toxins (Basel). 2014 Jul 14;6(7):2082-96.

17. Estrada-Gómez S, Vargas Muñoz LJ, Saldarriaga-Córdoba M, Quintana Castillo JC. Venom from Opisthacanthus elatus scorpion of Colombia, could be more hemolytic and less neurotoxic than thought. Acta Trop. 2016 Jan;153:70-8.

18. Barona J, Batista CV, Zamudio FZ, Gomez-Lagunas F, Wanke E, Otero $\mathrm{R}$, et al. Proteomic analysis of the venom and characterization of toxins specific for $\mathrm{Na}^{+}-$and $\mathrm{K}+$-channels from the Colombian scorpion Tityus pachyurus. Biochim Biophys Acta. 2006 Jan;1764(1):76-84.

19. Rincón-Cortés CA, Olamendi-Portugal T, Carcamo-Noriega EN, Santillán EG, Zuñiga FZ, Reyes-Montaño EA, et al. Structural and functional characterization of toxic peptides purified from the venom of the Colombian scorpion Tityus macrochirus. Toxicon. 2019 Nov;169:5-11.

20. Guerrero-Vargas JA, Mourão CBF, Quintero-Hernández V, Possani LD, Schwartz EF. Identification and Phylogenetic Analysis of Tityus pachyurus and Tityus obscurus Novel Putative $\mathrm{Na}(+)$-Channel Scorpion Toxins. PloS One. 2012 Feb 15;7:e30478.

21. Otero R, Navio E, Cespedes FA, Nunez MJ, Lozano L, Moscoso ER, et al. Scorpion envenoming in two regions of Colombia: clinical, epidemiological and therapeutic aspects. Trans R Soc Trop Med Hyg. 2004 Dec;98(12):74250.

22. Ward MJ, Ellsworth SA, Nystrom GS. A global accounting of medically significant scorpions: Epidemiology, major toxins, and comparative resources in harmless counterparts. Toxicon. 2018 Sep 1;151:137-55.

23. Gómez JP, Quintana JC, Arbeláez P, Fernández J, Silva JF, Barona J, et al. Picaduras por escorpión Tityus asthenes en Mutatá, Colombia: aspectos epidemiológicos, clínicos y toxinológicos. Biomedica. 2010;30(1):126-39.

24. Laemmli UK. Cleavage of structural proteins during the assembly of the head of bacteriophage T4. Nature. 1970 Aug 15;227(5259):680-5.

25. Doumas BT, Bayse DD, Borner DD, Carter RJ, Elevitch F, Garber CC, et al. A candidate Reference Method for determination of total protein in serum. II. Test for transferability. Clin Chem. 1981 Oct;27(10):1651-4.

26. Doumas BT, Bayse DD, Carter RJ, Peters Jr T, Schaffer R. A candidate Reference Method for determination of total protein in serum. I. Development and validation. Clin Chem. 1981 Oct;27(10):1642-50.

27. Zheng K, Wu L, He Z, Yang B, Yang Y. Measurement of the total protein in serum by biuret method with uncertainty evaluation. Measurement. 2017 Dec;112:16-21.

28. Istvan LJ, Istvan LS. GelAnalyzer 19.1. 2021.

29. Fernandez J, Gutierrez JM, Angulo Y, Sanz L, Juarez P, Calvete JJ, et al. Isolation of an acidic phospholipase A2 from the venom of the snake Bothrops asper of Costa Rica: biochemical and toxicological characterization. Biochimie. 2010 Mar;92(3):273-83.

30. Chen C, Li Z, Huang H, Suzek BE, Wu CH, UniProt Consortiium. A fast Peptide Match service for UniProt Knowledgebase. Bioinformatics. 2013 Nov 1;29(21):2808-9.

31. Wu CH, Yeh LSL, Huang H, Arminski L, Castro-Alvear J, Chen Y, et al. The Protein Information Resource. Nucleic Acids Res. 2003 Jan 1;31(1):345-7. 
32. Chen C, Li Z, Huang H, Suzek BE, Wu CH, Consortium U. A fast Peptide Match service for UniProt Knowledgebase. Bioinformatics. 2013 Nov 1;29(21):2808-9.

33. Wang G, Li X, Wang Z. APD3: the antimicrobial peptide database as a tool for research and education. Nucleic Acids Res. 2016 Jan 4;44(D1):D1087-93.

34. Estrada-Gomez S, Gomez-Rave L, Vargas-Munoz LJ, van der Meijden A. Characterizing the biological and biochemical profile of six different scorpion venoms from the Buthidae and Scorpionidae family. Toxicon. 2017 May;130:104-15.

35. Sharma PP, Fernández R, Esposito LA, González-Santillán E, Monod L. Phylogenomic resolution of scorpions reveals multilevel discordance with morphological phylogenetic signal. Proc Biol Sci. 2015 Apr 7;282(1804):20142953.

36. 36. Saez NJ, Senff S, Jensen JE, Er SY, Herzig V, Rash LD, et al. Spidervenom peptides as therapeutics. Toxins (Basel). 2010 Dec;2(12):2851-71.

37. D'Suze G, Schwartz EF, Garcia-Gomez BI, Sevcik C, Possani LD. Molecular cloning and nucleotide sequence analysis of genes from a cDNA library of the scorpion Tityus discrepans. Biochimie. 2009 Aug;91(8):1010-9.

38. Batista CV, del Pozo L, Zamudio FZ, Contreras S, Becerril B, Wanke $E$, et al. Proteomics of the venom from the Amazonian scorpion Tityus cambridgei and the role of prolines on mass spectrometry analysis of toxins. J Chromatogr B Analyt Technol Biomed Life Sci. 2004 Apr 15;803(1):55-66.

39. Batista CV, D'Suze G, Gomez-Lagunas F, Zamudio FZ, Encarnacion S, Sevcik C, et al. Proteomic analysis of Tityus discrepans scorpion venom and amino acid sequence of novel toxins. Proteomics. 2006 Jun;6(12):3718-27.

40. Garcia-Calvo M, Leonard RJ, Novick J, Stevens SP, Schmalhofer W, Kaczorowski GJ, et al. Purification, characterization, and biosynthesis of margatoxin, a component of Centruroides margaritatus venom that selectively inhibits voltage-dependent potassium channels. J Biol Chem. 1993 Sep 5;268(25):18866-74.

41. Grissmer S, Nguyen AN, Aiyar J, Hanson DC, Mather RJ, Gutman GA, et al. Pharmacological characterization of five cloned voltage-gated $\mathrm{K}+$ channels, types Kv1.1, 1.2, 1.3, 1.5, and 3.1, stably expressed in mammalian cell lines. Mol Pharmacol. 1994 Jun;45(6):1227-34.

42. de Oliveira UC, Candido DM, Dorce VA, Junqueira-de-Azevedo Ide $\mathrm{L}$. The transcriptome recipe for the venom cocktail of Tityus bahiensis scorpion. Toxicon. 2015 Mar;95:52-61.

43. de Paula Santos-da-Silva A, Candido DM, Nencioni ALA, Kimura LF, Prezotto-Neto JP, Barbaro KC, et al. Some pharmacological effects of Tityus obscurus venom in rats and mice. Toxicon. 2017 Feb;126:51-8.

44. Martin-Eauclaire MF, Pimenta AMC, Bougis PE, De Lima ME. Potassium channel blockers from the venom of the Brazilian scorpion Tityus serrulatus (Lutz and Mello, 1922). Toxicon. 2016 Sep 1;119:253-65.
45. Vargas Munoz LJ, Estrada-Gomez S, Vasquez J. Toxinas de venenos de serpientes y escorpiones, una fuente natural de moleculas con actividad antimicrobiana. CURARE. 2015;2(2).

46. Schwartz EF, Camargos TS, Zamudio FZ, Silva LP, Bloch C, Caixeta F, et al. Mass spectrometry analysis, amino acid sequence and biological activity of venom components from the Brazilian scorpion Opisthacanthus cayaporum. Toxicon. 2008 Jun 15;51(8):1499-1508.

47. Estrada-Gomez, S.; Vargas-Munoz, L.J.; Saldarriaga-Cordoba, M.; Cifuentes, Y.; Perafan, C. Identifying different transcribed proteins in the newly described Theraphosidae Pamphobeteus verdolaga. Toxicon. 2017 Apr;129:81-88.

48. Cheng TC, Long RW, Wu YQ, Guo YB, Liu DL, Peng L, et al. Identification and characterization of toxins in the venom gland of the Chinese bird spider, Haplopelma hainanum, by transcriptomic analysis. Insect Sci. 2016 Jun;23(3):487-99.

49. Jiang L, Peng L, Chen J, Zhang Y, Xiong X, Liang S. Molecular diversification based on analysis of expressed sequence tags from the venom glands of the Chinese bird spider Ornithoctonus huwena. Toxicon. 2008 Jun 15;51(8):1479-89.

50. Yuan C, Jin Q, Tang X, Hu W, Cao R, Yang S, et al. Proteomic and peptidomic characterization of the venom from the Chinese bird spider, Ornithoctonus huwena Wang. J Proteome Res. 2007 Jul;6(7):2792-801.

51. Borges MH, Figueiredo SG, Leprevost FV, De Lima ME, Cordeiro MN Diniz MR, et al. Venomous extract protein profile of Brazilian tarantula Grammostola iheringi: searching for potential biotechnological applications. J Proteomics. 2016 Mar 16;136:35-47.

52. Liao Z, Cao J, Li S, Yan X, Hu W, He Q, et al. Proteomic and peptidomic analysis of the venom from Chinese tarantula Chilobrachys jingzhao. Proteomics. 2007 Jun; 7(11):1892-1907.

53. Santibáñez-López CE, Cid-Uribe JI, Batista CVF, Ortiz E, Possani LD. Venom Gland Transcriptomic and Proteomic Analyses of the Enigmatic Scorpion Superstitionia donensis (Scorpiones: Superstitioniidae), with Insights on the Evolution of Its Venom Components. Toxins (Basel). 2016 Dec;8(12):367.

54. He Y, Zhao R, Di Z, Li Z, Xu X, Hong W, et al. Molecular diversity of Chaerilidae venom peptides reveals the dynamic evolution of scorpion venom components from Buthidae to non-Buthidae. J Proteomics. 2013 Aug 26;89:1-14.

55. Ma Y, He Y, Zhao R, Wu Y, Li W, Cao Z. Extreme diversity of scorpion venom peptides and proteins revealed by transcriptomic analysis: implication for proteome evolution of scorpion venom arsenal. J Proteomics. 2012 Feb 16;75(5):1563-76. 